This is the peer reviewed version of the following article:

Andrés M.A., Carné-Sánchez A., Sánchez-Laínez J., Roubeau O., Coronas J., Maspoch D., Gascón I.. Ultrathin Films of Porous Metal-Organic Polyhedra for Gas Separation.

Chemistry - A European J ournal, (2020). 26. : 143 - . 10.1002/chem.201904141,

which has been published in final form at https://dx.doi.org/10.1002/chem.201904141. This article may be used for non-commercial purposes in accordance with Wiley Terms and Conditions for Use of Self-Archived Versions. 


\title{
Ultrathin films of porous metal-organic polyhedra for gas separation
}

\author{
Miguel A. Andrés ${ }^{[a, b]}$, Arnau Carné-Sánchez ${ }^{[c]}$, Javier Sánchez-Laínez ${ }^{[b, d]}$, Olivier Roubeau ${ }^{[b]}$, Joaquín \\ Coronas $^{[\mathrm{b}, \mathrm{d}]}$, Daniel Maspoch ${ }^{*[\mathrm{c}, \mathrm{e}]}$, Ignacio Gascón ${ }^{*[a, b]}$
}

\begin{abstract}
Ultrathin films of a robust $\mathrm{Rh}(\mathrm{II})$-based porous metalorganic polyhedra (MOP) have been obtained. Homogeneous and compact monolayer films (ca. $2.5 \mathrm{~nm}$ thick) were first formed at the air-water interface, deposited onto different substrates and characterized using spectroscopic methods, scanning transmission electron microscopy and atomic force microscopy. As a proof of concept, the gas separation performance of MOP supported membranes has been also evaluated. Selective MOP ultrathin films (thickness ca. $60 \mathrm{~nm}$ ) exhibit remarkable $\mathrm{CO}_{2}$ permeance and $\mathrm{CO}_{2} / \mathrm{N}_{2}$ selectivity, demonstrating the great combined potential of MOP and Langmuir-based techniques in separation technologies.
\end{abstract}

The current technology for capturing $\mathrm{CO}_{2}$ at the emission points relies on its absorption in alkanolamine aqueous solutions. This solution-based method is highly selective but requires high regeneration temperatures, which reduces its recyclability and increases its cost making difficult its implementation at large scale. ${ }^{[1]}$ Alternatively, $\mathrm{CO}_{2}$ separation by membranes has emerged as an environmentally friendly and more cost effective method, ${ }^{[2]}$ and can be applied to other processes of interest such as the upgrading of biogas to biomethane. ${ }^{[3]}$ However, current membranes lack the capacity to treat huge amounts of flue gas with the required selectivity for $\mathrm{CO}_{2 .}{ }^{[4]}$ Accordingly, membranes able to achieve high gas flux (permeance) while maintaining a high selectivity for $\mathrm{CO}_{2}$ are intensively sought. One way of increasing gas flux is decreasing the thickness of the membrane because both parameters are inversely proportional. Therefore, ultrathin porous films with thicknesses below $100 \mathrm{~nm}$ have the potential to enhance membrane performance by increasing the flux of gas through the membrane without losing $\mathrm{CO}_{2}$ selectivity. ${ }^{[5}$, 6] Langmuir-Blodgett (LB) is a technique especially suitable for this purpose as it enables the self-assembly of monolayer films at the

[a] M. A. Andrés, Dr. I Gascón

Departamento de Química Física and Instituto de Nanociencia de Aragón (INA), Universidad de Zaragoza, 50009 Zaragoza (Spain). E-mail: igascon@unizar.es

[b] M. A. Andrés, Dr. J. Sánchez-Laínez, Dr. Olivier Roubeau, Prof. Dr. J. Coronas, Dr. I Gascón

Instituto de Ciencia de Materiales de Aragón (ICMA), CSIC and Universidad de Zaragoza, 50009 Zaragoza, Spain.

[c] Dr. A. Carné-Sánchez, Prof. Dr. D. Maspoch

Catalan Institute of Nanoscience and Nanotechnology (ICN2), CSIC and The Barcelona Institute of Science and Technology, Campus UAB, Bellaterra, 08193 Barcelona, Spain.

E-mail: daniel.maspoch@icn2.cat

[d] Dr. J. Sánchez-Laínez, Prof. Dr. J. Coronas

Chemical and Environmental Engineering Department and Instituto de Nanociencia de Aragón (INA) Universidad de Zaragoza, 50018 Zaragoza, Spain

[e] Prof. Dr. D. Maspoch

ICREA, Pg. Lluís Companys 23, 08010 Barcelona, Spain

Supporting information for this article is given via a link at the end of the document. air-liquid interface, and the subsequent transfer of such films to permeable supports to fabricate multilayer membranes with precise control on the thickness of the selective layer. ${ }^{[7]}$ However, this potential remains under-exploited because the majority of porous materials lack the solution processability required for the LB method. Accordingly, the use of the LB technique to fabricate ultrathin membranes for $\mathrm{CO}_{2}$ capture has been restricted to soluble organic molecules ${ }^{[7]}$ and polymers of intrinsic porosity (PIMs) ${ }^{[8,9]}$

Herein, we expand the scope of the LB method to discrete metal-organic polyhedral molecules (MOPs) fabricating MOPbased ultrathin films. MOPs are nanosized molecules of 2-5 nm synthesised from the self-assembly of metal ions and organic linkers, which can be soluble in different polar and non-polar liquids and permanently porous in solid state. ${ }^{[10-14]}$ In this communication, we show how robust $\mathrm{Rh}$ (II)-based MOPs can be assembled at the air-water interface through the LB technique forming homogenous 2-3 nm thick monolayer films. For this study, we selected a cuboctahedral Rh-MOP functionalized with pendant aliphatic chains with formula: $\left[\mathrm{Rh}_{2}\left(\mathrm{C}_{12}-\mathrm{bdc}\right)_{2}\right]_{12}$ (hereafter $\mathrm{C}_{12}$ RhMOP; $\mathrm{C}_{12}$-bdc $=$ 5-dodecoxybenzene-1,3-dicarboxylate; Figure 1a) due to its hydrolytic stability and good solubility in organic solvents such as dichloromethane (DCM). ${ }^{[15,16]}$ High hydrolytic stability of MOPs is a prerequisite for the LB method because the assembled monolayers are formed on top of the water phase. Thus, MOPs based on labile coordination bonds such as $\mathrm{Cu}(\mathrm{II})$-carboxylate were not considered for this study. Furthermore, the pendant aliphatic chains of $\mathrm{C}_{12} \mathrm{RhMOP}$ are expected to facilitate the formation of a compact monolayer at the air-water interface and to favour the cohesion among deposited multilayers. Moreover, previous studies ${ }^{[16]}$ have shown that $\mathrm{C}_{12} \mathrm{RhMOP}$ displays a negligible $\mathrm{N}_{2}$ adsorption at $77 \mathrm{~K}(0.17$ and $0.82 \mathrm{~N}_{2}$ moles per MOP mol at $\mathrm{P} / \mathrm{P}_{0} \approx 0.1$ and $\mathrm{P} / \mathrm{P}_{0} \approx 0.95$, respectively) and a significant $\mathrm{CO}_{2}$ adsorption at $195 \mathrm{~K}$ (9 and 22 mol of $\mathrm{CO}_{2}$ per MOP mol at $\mathrm{P} / \mathrm{P}_{0} \approx 0.1$ and $\mathrm{P} / \mathrm{P}_{0} \approx 0.95$, respectively), making it an interesting candidate for $\mathrm{CO}_{2} / \mathrm{N}_{2}$ separation. Multiple $\mathrm{C}_{12} \mathrm{RhMOP}$ monolayer films were thus deposited on the permeable polymer poly[1-(trimethylsilyl)-1propyne] (PTMSP) to fabricate a multilayer membrane with the desired MOP film thickness. The $\mathrm{CO}_{2} / \mathrm{N}_{2}$ selectivity of the PTMSP membrane at 1 bar and $35^{\circ} \mathrm{C}$ was significantly increased from 4.1 to 10.1 after 30 deposition cycles of $\mathrm{C}_{12} \mathrm{RhMOP}$ monolayers while keeping high the $\mathrm{CO}_{2}$ permeance (195 GPU), thereby demonstrating the potential of molecularly thin MOP films for the $\mathrm{CO}_{2} / \mathrm{N}_{2}$ separation. 
We initially prepared a diluted $\mathrm{C}_{12}$ RhMOP solution in DCM $\left(2.8 \cdot 10^{-6} \mathrm{M}\right)$ to study Langmuir film formation. Then, $1000-1200$ $\mu \mathrm{L}$ of the $\mathrm{C}_{12}$ RhMOP solution (i.e. the total mass of $\mathrm{C}_{12} \mathrm{RhMOP}$ employed was $0.04 \mathrm{mg}$ ) were spread on the water subphase. After solvent evaporation (ca. $10 \mathrm{~min}$ ), the floating molecules were compressed to induce their assembly into a monolayer film (Figure 1b). The surface pressure - area isotherm ( $\pi-A)$ reveals that the self-assembly process starts when $\mathrm{C}_{12} \mathrm{RhMOP}$ is compressed to an area of $8 \mathrm{~nm}^{2} /$ molecule (Figure 1c). Further compression causes a steep increase of the surface pressure indicating the formation of the film. The maximum slope at ca. 5 $\mathrm{nm}^{2} /$ molecule is in good agreement with the estimated lateral size of a single molecule with extended alkyl substituents at ca. $5.3 \mathrm{~nm}$ (see Figure S1 in the Supporting Information), which would indicate that the film formation involves a partial interdigitation of the alkyl arms. Brewster angle microscopy images obtained during $\mathrm{C}_{12} \mathrm{RhMOP}$ compression reveal that the water surface is completely covered by a $\mathrm{C}_{12} \mathrm{RhMOP}$ monolayer film at a surface pressure of $25 \mathrm{mN} \cdot \mathrm{m}^{-1}$ (see Figure $\mathrm{S} 2$ in the Supporting Information). Increasing the surface pressure above $37.5 \mathrm{mN} \cdot \mathrm{m}^{-1}$ causes the collapse of the $\mathrm{C}_{12} \mathrm{RhMOP}$ film, which agrees with the change in the slope of the surface pressure in the $\pi-A$ isotherm and the value determined from the surface potential measurements (see Figure S3 in the Supporting Information).
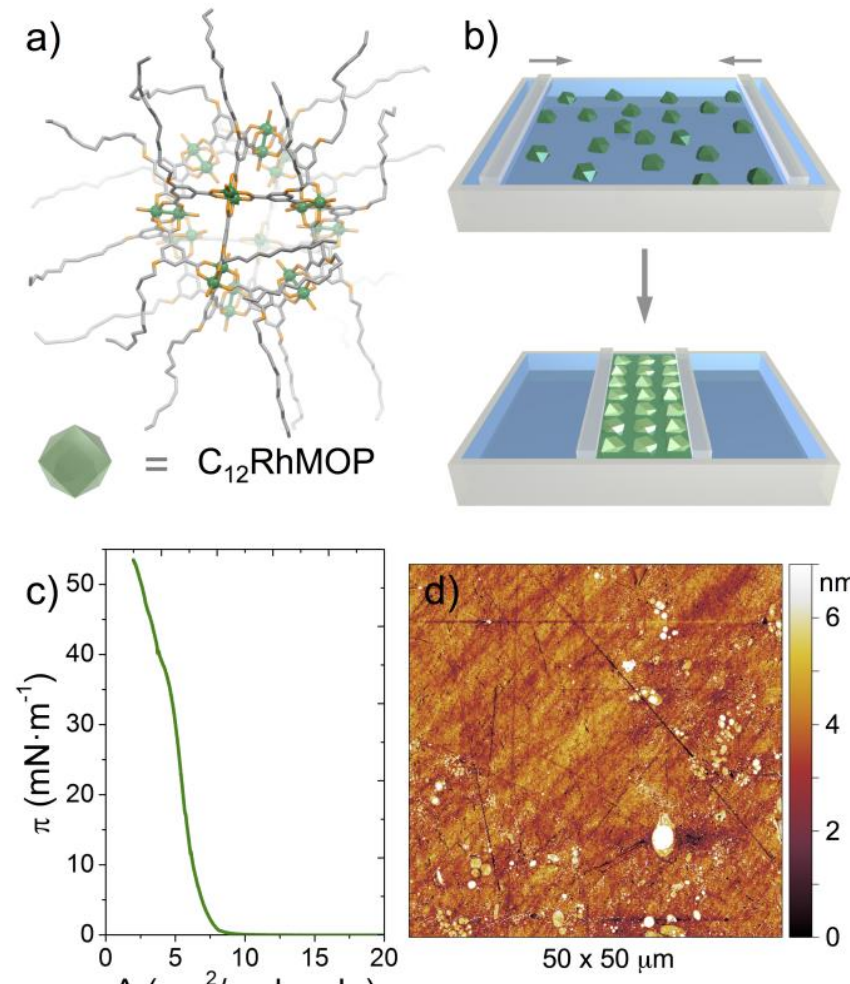

of the related $\mathrm{C}_{12} \mathrm{CuMOP}$ and its schematic representation as a cuboctahedron. ${ }^{[17]}$ Colour code: Rh (green), C (grey), O (orange). (b) Scheme of the formation of a continuous Langmuir film upon compression of $\mathrm{C}_{12} \mathrm{RhMOP}$ molecules expanded at the air-water interface. (c) $\pi-A$ isotherm obtained from the compression of $\mathrm{C}_{12} \mathrm{RhMOP}$. (d) $A F M$ image of a single monolayer of $\mathrm{C}_{12} \mathrm{RhMOP}$ deposited on quartz substrate. Note here that the observed scratches correspond to defects on the surface of the quartz plates used since phase images confirmed that the samples were homogeneous.

Next, monolayer films compressed at surface pressures between 15 and $35 \mathrm{mN} \cdot \mathrm{m}^{-1}$ were transferred onto mica and quartz substrates. Two different deposition methods were tested: vertical transfer (Langmuir-Blodgett films) and horizontal transfer (Langmuir-Schaefer, LS, films). Irrespectively of the deposition method employed, the UV-Vis spectra of the $\mathrm{C}_{12}$ RhMOP deposited on quartz reveal the presence of two bands at 265 and $315 \mathrm{~nm}$, which are in perfect agreement with the UV-Vis spectra of $\mathrm{C}_{12} \mathrm{RhMOP}$ in solution. This confirms the stability of $\mathrm{C}_{12} \mathrm{RhMOP}$ throughout the whole assembly process (see Figure S4 in the Supporting Information).

However, the absorbance values obtained for the monolayer films transferred horizontally are systematically higher than for those transferred vertically, at all pressures tested, thereby suggesting a better quality and homogeneity for the LS films (see Figure S5 in the Supporting Information). UV-Vis measurements also indicate that the film absorbance values are lower when surface pressures above $25 \mathrm{mN} \cdot \mathrm{m}^{-1}$ are employed. These low absorbance values reflect a poorer film coverage, probably because the film becomes too rigid above this surface pressure, making the transfer less effective. These observations are in line with atomic force microscopy (AFM) measurements, as complete substrate coverage is achieved when monolayer films are transferred at a surface pressure of $25 \mathrm{mN} \cdot \mathrm{m}^{-1}$ (Figure $1 \mathrm{~d}$ and Figures S6 and S7 in the Supporting Information). On the contrary, a lower film coverage is observed when transfers were performed at $35 \mathrm{mN} \cdot \mathrm{m}^{-1}$, due to the presence of domains with different thicknesses. Altogether, these results confirm that horizontal transfer at a surface pressure of $25 \mathrm{mN} \cdot \mathrm{m}^{-1}$ allows the formation of homogeneous $\mathrm{LS} \mathrm{C}_{12} \mathrm{RhMOP}$ monolayer films on surfaces with an average height of ca. $2.5 \mathrm{~nm}$ (see Figure 1d and Figure S7 in the Supporting Information). Interestingly, no significant differences in terms of homogeneity are observed when using different types of flat substrate, i.e. the inorganic hydrophilic mica, quartz or the hydrophobic PTSMP organic polymer (see below).

With the pressure and the deposition method of $\mathrm{C}_{12} \mathrm{RhMOP}$ monolayers optimized, a quartz crystal microbalance (QCM) was then used to study the multilayer deposition. A linear correlation between the deposited mass of $\mathrm{C}_{12} \mathrm{RhMOP}$ and the number of cycles is found (see Figure S8 in the Supporting Information), with an almost constant deposition of $0.31 \mu \mathrm{g} \cdot \mathrm{cm}^{-2}$ for each MOP monolayer. This corresponds to $5.8 \mathrm{~nm}^{2} /$ molecule thus very similar to the area observed at the air-water interface. This accounts for the film quality, as defects in one deposition would cause poorer deposition of the subsequent monolayers.

The fabrication of MOP multilayer films with a controlled thickness offers several possibilities for the implementation of MOPs in membrane technology for gas separation. However, to our knowledge, MOPs have been only used in this field as fillers for mixed matrix membranes with micrometric thicknesses. [18-21] As a proof of concept, in order to demonstrate how the LS deposition can be used for the fabrication of MOP membranes with thicknesses in the nanometre range and supported on a porous substrate, we studied the multilayer deposition of $\mathrm{C}_{12}$ RhMOP monolayers onto PTMSP supports. PTMSP is an ultrapermeable polymer showing very high gas permeability and low $\mathrm{CO}_{2} / \mathrm{N}_{2}$ selectivity. Moreover, it can be easily processed into very flat membranes by drop-casting and therefore, it is a suitable support for the deposition of LB/LS films of different substances. ${ }^{[8,}$ 9] 
To this end, different multilayer films were fabricated by depositing 3, 5, 10 and $20 \mathrm{C}_{12}$ RhMOP monolayers onto PTMSP supports using the optimised conditions (LS deposition; surface pressure $\left.=25 \mathrm{mN} \cdot \mathrm{m}^{-1}\right)$. The resulting multilayer $\mathrm{C}_{12} \mathrm{RhMOP}$ films were then characterized by AFM and X-ray photoelectron spectroscopy (XPS) (see Figure 2b, Figures S9, S11 and S12 and Table S1 in the Supporting Information). Although some small pinholes and $\mathrm{C}_{12} \mathrm{RhMOP}$ agglomerations are also present, an overall good coverage of the PTMSP support is observed, even after the deposition of only three $\mathrm{C}_{12} \mathrm{RhMOP}$ monolayers. The thickness of a single monolayer is estimated to be ca. $2.5 \mathrm{~nm}$ measuring the height in different film defects and borders (see Figure S7 in the Supporting Information). The size and number of film defects diminishes gradually with the number of $\mathrm{C}_{12} \mathrm{RhMOP}$ monolayers transferred. An almost defect-free MOP multilayer is obtained after the deposition of ca. 20 LS C $_{12}$ RhMOP monolayers.

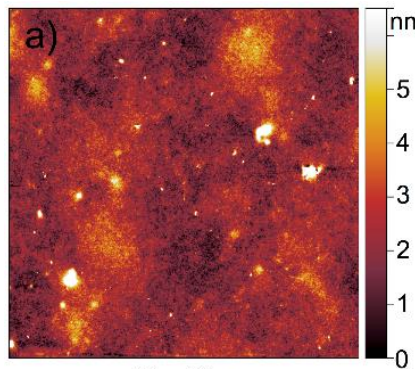

$10 \times 10 \mu \mathrm{m}$

c)

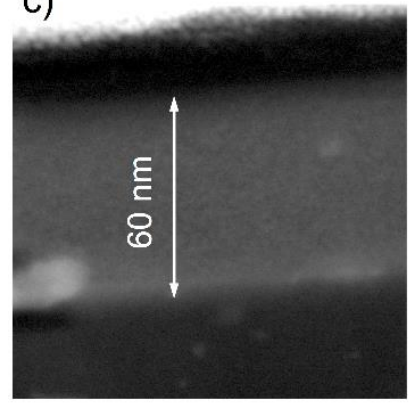

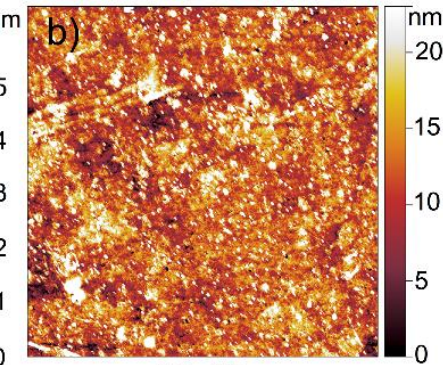

$20 \times 20 \mu \mathrm{m}$

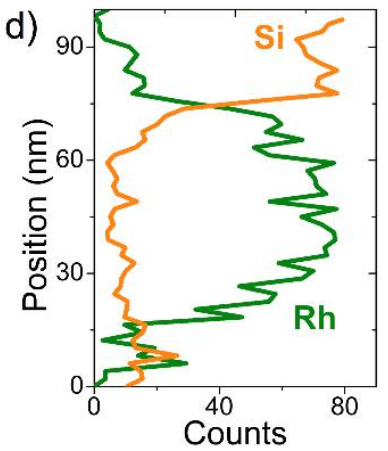

Figure $2(a, b)$ AFM images of a bare PTMSP substrate (a) and a PTMSP substrate covered with $20 \mathrm{C}_{12}$ RhMOP monolayers (b). (c) STEM-HAADF image from a lamella extracted from a PTMSP substrate covered with 30 $\mathrm{C}_{12}$ RhMOP monolayers. (d) Typical EDS signal of the Rh L $\alpha$ and Si Ka peaks along the lamella profile.

To obtain a more detailed characterization of $\mathrm{C}_{12} \mathrm{RhMOP}$ multilayer films deposited onto PTMSP, a lamella of a sample obtained after depositing $30 \quad \mathrm{C}_{12} \mathrm{RhMOP}$ monolayers was extracted for analysis by scanning transmission electron microscopy (STEM). The sequence of images of the lamella thinning can be found in the Supporting Information (Figure S10). Figure $2 c$ shows a STEM-HAADF image of the lamella in which it is possible to distinguish the MOP multilayer with a different contrast to that of the PTMSP support at the bottom and the C/Pt coatings on top. According to the images obtained, the thickness of the MOP film is close to $60-65 \mathrm{~nm}$. These values are in good agreement with the thickness derived from AFM measurements (each monolayer is ca. $2.5 \mathrm{~nm}$ thick). Moreover, the composition of the lamella was analysed by energy-dispersive $\mathrm{X}$-ray spectroscopy (EDS). Figure $2 \mathrm{~d}$ shows the Rh La $(2.697 \mathrm{eV})$ and $\mathrm{Si} \mathrm{Ka}(1.740 \mathrm{eV})$ peaks counts along the lamella profile, confirming the presence of $\mathrm{Rh}$ in the MOP multilayer film and $\mathrm{Si}$ in the PTMSP support. Moreover, the deduced thickness of the MOP layer derived from the EDS profiles is also consistent with the STEM-HAADF image, at ca. $60 \mathrm{~nm}$.

The separation performance of $\mathrm{C}_{12} \mathrm{RhMOP}$ supported membranes, consisting of 20 to $30 \mathrm{MOP}$ monolayers deposited onto PTMSP supports was tested in $\mathrm{CO}_{2} / \mathrm{N}_{2}$ separation for postcombustion carbon capture (temperature $35^{\circ} \mathrm{C}$, feed pressures 1 to 3 bar, $\mathrm{CO}_{2} / \mathrm{N}_{2}$ mixture composition $10 / 90$ in volume). $\mathrm{CO}_{2}$ permeance and $\mathrm{CO}_{2} / \mathrm{N}_{2}$ selectivity values for the different membranes analysed are shown in Figure 3. Pure PTMSP membranes present a high $\mathrm{CO}_{2}$ permeance (415 GPU at 1 bar) but low $\mathrm{CO}_{2} / \mathrm{N}_{2}$ selectivity (4.2) in agreement with previous works. ${ }^{[8,9,22]}$
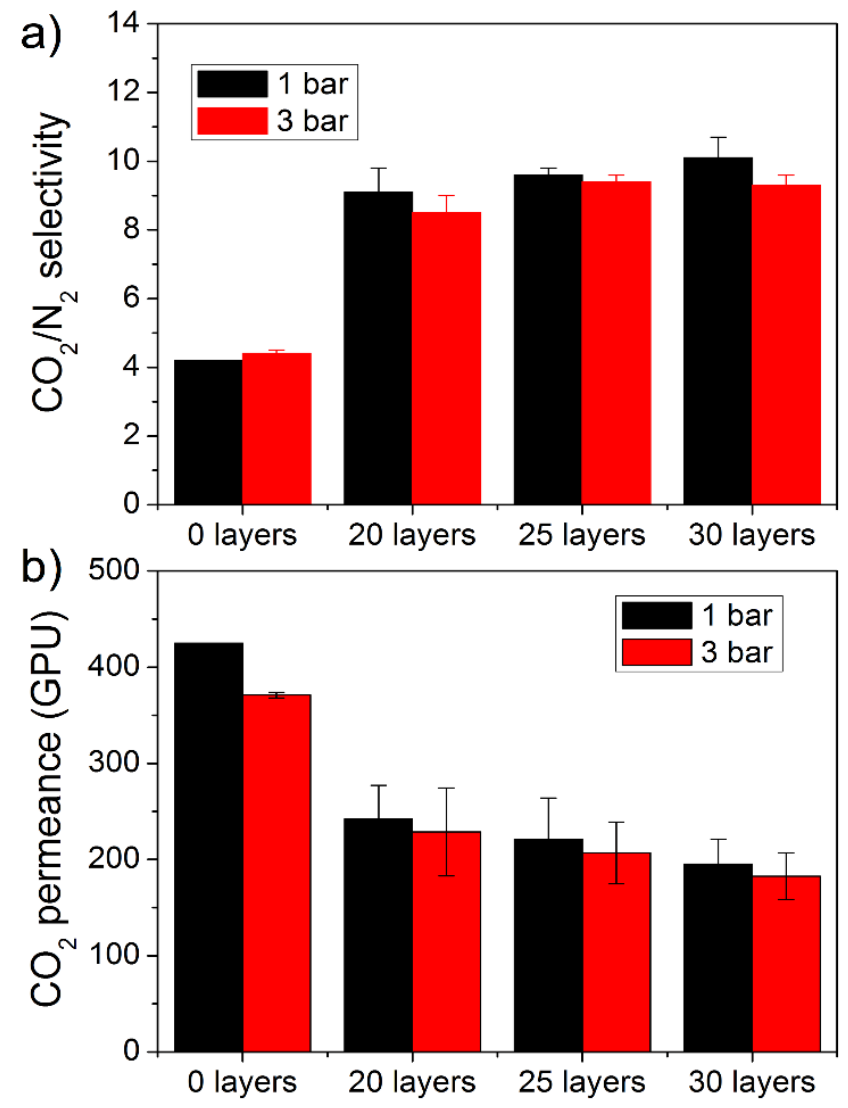

Figure 3. (a,b) $\mathrm{CO}_{2} / \mathrm{N}_{2}$ selectivity (a) and $\mathrm{CO}_{2}$ permeance (b) of bare PTMSP (0 layers) and MOP supported membranes formed, respectively, by 20,25 and $30 \mathrm{C}_{12}$ RhMOP monolayers deposited onto PTMSP. Error bars were determined from at least 2 independent measurements.

The deposition of 20 to $30 \mathrm{C}_{12} \mathrm{RhMOP}$ monolayers increases the $\mathrm{CO}_{2} / \mathrm{N}_{2}$ selectivity at 1 bar up to values of 9.1 and 10.1 (Figure 3a), respectively, while maintaining the $\mathrm{CO}_{2}$ permeance above $195 \mathrm{GPU}$ (Figure 3b). When the feed pressure increases from 1 to 3 bar, $\mathrm{CO}_{2}$ permeance values diminish by ca. $6 \%$ for MOP supported films. However, this reduction is ca. $13 \%$ for pure PTMSP supports. This difference is indicative of the formation of dense $\mathrm{C}_{12} \mathrm{RhMOP}$ multilayers, as shown in STEM images.

Comparing these data to previous studies, ${ }^{[8,9]}$ where different polymers of intrinsic microporosity (PIMs) were deposited onto PTMSP substrates, it can be highlighted that the $\mathrm{CO}_{2}$ permeance values obtained with $30 \mathrm{C}_{12} \mathrm{RhMOP}$ monolayers deposited onto PTMSP (195 GPU at 1 bar) are significantly higher than those obtained when stacking the same number of PIM 
monolayers (134 GPU for PIM-TMN-Trip films and 118 GPU for PIM-EA-TB(H2)). However, $\mathrm{CO}_{2} / \mathrm{N}_{2}$ selectivity values are slightly lower for MOP supported films (10.1) than for PIM-TMN-Trip $(12.1)^{[9]}$ and PIM-EA-TB $\left(\mathrm{H}_{2}\right)(13.8)^{[8]}$ supported films. This tendency is somehow expected as the higher is the permeability for a membrane, the lower is generally the selectivity.

In conclusion, we have demonstrated that the LB method can be employed to induce the self-assembly of $\mathrm{C}_{12} \mathrm{RhMOP}$ into dense and ultrathin porous films, and that these films can be used as selective materials in multilayer membranes for efficient $\mathrm{CO}_{2}$ separation. These results pave the way for the implementation of MOPs in separation technologies as the LB technique enables to fabricate large area membranes using minute amounts of active material. We believe that the versatility and ease functionalization of MOPs will provide a wide catalogue of MOP-based membranes with potential in gas separation and other applications.

\section{Experimental Section}

\section{Thin film formation at the air-water interface}

Film formation at the air-water interface (Langmuir films) was first optimized using a commercial Langmuir Teflon trough (NIMA, Model 702) with a symmetrical double-barrier configuration and dimensions of $720 \times$ $100 \mathrm{~mm}$. This device was used to register surface pressure vs. area (ח-A) isotherms and Brewster angle microscopy (BAM) images. These images were obtained using a KSV NIMA Micro BAM, equipped with a red laser light source $(50 \mathrm{~mW}, 659 \mathrm{~nm})$ with a fixed incidence angle of $53.1^{\circ}$. Another apparatus (KSV-NIMA, model KN 2003) with dimensions of $580 \mathrm{~mm} \times 145$ $\mathrm{mm}$, also equipped with a symmetrical double-barrier system, was used for the fabrication of LB and LS films onto different substrates: quartz, mica, QCM discs and PTMSP dense membranes. Both troughs were kept inside closed cabinets in a dedicated laboratory with special care to limit the presence of dust and at constant temperature $\left(20 \pm 1^{\circ} \mathrm{C}\right)$. Films were compressed at constant speed $\left(8 \mathrm{~cm}^{2} \cdot \mathrm{min}^{-1}\right)$. Ultra-pure Milli- $Q$ water $(\rho=$ 18.2 $\mathrm{M} \Omega \cdot \mathrm{cm}$ ) was used as subphase in all the experiments. Surface pressure was continuously registered in both devices using Wilhelmy balances with a filter paper plate.

\section{Thin film deposition onto substrates}

LB films were transferred onto solid substrates by vertical dipping at a constant speed of $1 \mathrm{~mm} \cdot \mathrm{min}^{-1}$. For LS film fabrication, substrates were held horizontally and parallel to the water surface using a vacuum pump based horizontal dipping clamp. When the desired surface pressure was reached, the substrate was approached to the surface at a vertical speed of $1 \mathrm{~mm} \cdot \mathrm{min}^{-1}$. Once the substrate touched the water surface, it was withdrawn at a vertical speed of $10 \mathrm{~mm} \cdot \mathrm{min}^{-1}$. After each transfer, LS films were dried with $\mathrm{N}_{2}$ at ambient temperature, and the procedure was repeated as many times as necessary to obtain films with the desired number of MOP monolayers.
(T43_17R and E31_17R research groups). ICN2 is supported by the Severo Ochoa program from Spanish MINECO (SEV-20170706). A.C.-S. thanks the Spanish MINECO for Juan de la Cierva fellowship (IJCl-2016-29802), J. S.-L. and M.A.A thank the Spanish Education Ministry Program FPU2014 for their Ph.D. grants. The microscopy work was carried out in the Laboratorio de Microscopias Avanzadas at the Instituto de Nanociencia de Aragon (LMA-INA, Universidad de Zaragoza).

\section{Keywords: Metal-organic polyhedra, Langmuir-Blodgett} technique, Thin films, $\mathrm{CO}_{2}$ separation

[1] B. Dutcher, M. Fan, A. G. Russell, ACS Appl. Mater. Interfaces 2015, 7, 2137-2148.

[2] N. Du, H. B. Park, M. M. Dal-Cin, M. D. Guiver, Energy Environ. Sci. 2012 $5,7306-7322$.

[3] V. Vrbová, K. Ciahotný, Energy Fuels 2017, 31, 9393-9401.

[4] M. Wang, J. Zhao, X. Wang, A. Liu, K. K. Gleason, J. Mater. Chem. A 2017, 5, 8860-8886.

[5] R. Selyanchyn, S. Fujikawa, Sci. Technol. Adv. Mater. 2017, 18, 816-827.

[6] K. Xie, Q. Fu, G. G. Qiao, P. A. Webley, J. Membr. Sci., 2019, 572, 38-

60. M. Wang, V. Janout, S. L. Regen, Acc. Chem. Res. 2013, 46, 2743-2754 [8] J. Benito, J. Sánchez-Laínez, B. Zornoza, S. Martín, M. Carta, R. Malpass-Evans, C. Téllez, N. B. McKeown, J. Coronas, I. Gascón, ChemSusChem 2017, 10, 4014-4017.

[9] J. Benito, J. Vidal, J. Sánchez-Laínez, B. Zornoza, C. Téllez, S. Martín, K. J. Msayib, B. Comesaña-Gándara, N. B. McKeown, J. Coronas, I. Gascón J. Colloid Interface Sci. 2019, 536, 474-482.

[10] J.-R. Li, H.-C. Zhou, Nat. Chem. 2010, 2, 893.

[11] C. A. Rowland, G. R. Lorzing, E. J. Gosselin, B. A. Trump, G. P. A. Yap, C. M. Brown, E. D. Bloch, J. Am. Chem. Soc. 2018, 140, 11153-11157.

[12] W.-H. Xing, H.-Y. Li, X.-Y. Dong, S.-Q. Zang, J. Mater. Chem. A 2018, 6, 7724-7730.

[13] M. Eddaoudi, J. Kim, J. B. Wachter, H. K. Chae, M. O'Keeffe, O. M. Yaghi, J. Am. Chem. Soc. 2001, 123, 4368-4369.

[14] S. Furukawa, N. Horike, M. Kondo, Y. Hijikata, A. Carné-Sánchez, P. Larpent, N. Louvain, S. Diring, H. Sato, R. Matsuda, R. Kawano, S. Kitagawa, Inorg. Chem. 2016, 55, 10843-10846.

[15] R. Kawano, N. Horike, Y. Hijikata, M. Kondo, A. Carné-Sánchez, P. Larpent, S. Ikemura, T. Osaki, K. Kamiya, S. Kitagawa, S. Takeuchi, S Furukawa, Chem 2017, 2, 393-403.

[16] A. Carné-Sánchez, G. A. Craig, P. Larpent, T. Hirose, M. Higuchi, S. Kitagawa, K. Matsuda, K. Urayama, S. Furukawa, Nat Commun 2018 9, 2506.

[17] H. Furukawa, J. Kim, K. E. Plass, O. M. Yaghi, J. Am. Chem. Soc. 2006, 128, 8398-8399.

[18] E. V. Perez, K. J. Balkus, J. P. Ferraris, I. H. Musselman, J. Membr. Sci., 2014, 463, 82-93.

[19] M. Kitchin, J. Teo, K. Konstas, C. H. Lau, C. J. Sumby, A. W. Thornton, C. J. Doonan, M. R. Hill, J. Mater. Chem. A 2015, 3, 15241-15247.

[20] C. R. P. Fulong, J. Liu, V. J. Pastore, H. Lin, T. R. Cook, Dalton Trans. 2018, 47, 7905-7915.

[21] X. Liu, X. Wang, A. V. Bavykina, L. Chu, M. Shan, A. Sabetghadam, H. Miro, F. Kapteijn, J. Gascon, ACS Appl. Mater. Interfaces, 2018, 10, 21381 21389.

[22] S. D. Bazhenov, I. L. Borisov, D. S. Bakhtin, A. N. Rybakova, V. S. Khotimskiy, S. P. Molchanov, V. V. Volkov, Green Energy Environ. 2016, 1, 235 245.

\section{Acknowledgment}

This work was supported by the Spanish MINECO (projects RTI2018-095622-B-I00, MAT2016-78257-R, MAT2016-77290-R and MAT2017-86826-R), the Catalan AGAUR (project 2017 SGR 328), the ERC under the EU-FP7 (ERC-Co 615954), the CERCA Program/Generalitat de Catalunya and the Aragon Government 


\section{COMMUNICATION}

The fabrication of compact and dense porous metalorganic polyhedra (MOP) ultrathin films offers several advantages for the development of MOP-based applications in gas separation. MOP supported membranes obtained by successive Rh(II)-based MOP monolayer deposition can be applied for efficient $\mathrm{CO}_{2}$ separation.
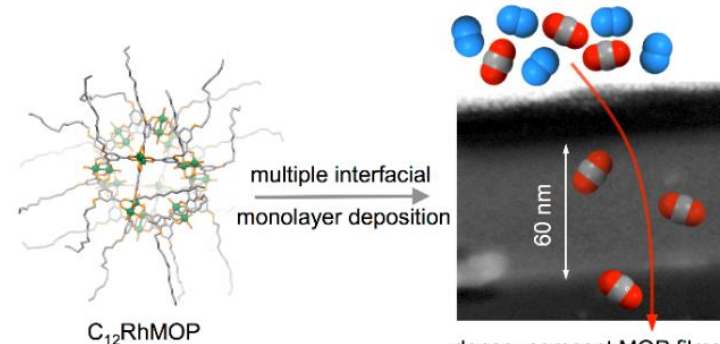

dense, compact MOP films
Miguel A. Andrés, Arnau

Carné-Sánchez, Javier Sánchez-Laínez, Olivier Roubeau, Joaquín Coronas, Daniel Maspoch*, Ignacio Gascón*

Page No. - Page No.

\section{Title}

